\title{
Substance use preferences and sexually transmitted infections among Canadian post-secondary students
}

This article was published in the following Dove Press journal:

Patient Preference and Adherence

\section{Nway Mon Kyaw Soe' \\ Yelena Bird' \\ Michael Schwandt ${ }^{2}$ \\ John Moraros'}

'School of Public Health, University of Saskatchewan, Saskatoon, SK, Canada; ${ }^{2}$ Fraser Health Authority, Surrey, BC, Canada

Correspondence: John Moraros School of Public Health, University of Saskatchewan, 104 Clinic Place, E-Wing Health Sciences, Room 3320, Saskatoon, SK, S7N 2Z4, Canada

Tel +I 3069668578

Email john.moraros@usask.ca
Background: In Canada, substance use is one of the key predisposing factors that may lead to risky sexual behaviors among post-secondary students. There is considerable economic burden and significant public health concern posed by substance use and sexually transmitted infections (STIs). The purpose of this study was to examine the prevalence of substance use preferences (alcohol, cannabis, and other drugs) and its association with STIs among Canadian post-secondary students.

Materials and methods: This is a cross-sectional study using data from the National College Health Assessment II, Spring 2016 survey conducted by the American College Health Association. There were 31,642 sexually active participants, representing 41 post-secondary institutions in Canada. Descriptive analysis and logistic regression were conducted to estimate the effect of substance use preferences on STIs.

Results: This study found that participants reported being current users of alcohol $(80 \%)$, cannabis (23\%), and other drugs (8\%). Additionally, 3.96\% of the participants self-reported being diagnosed or treated for an STI in the last 12 months. Multivariate logistic analysis revealed current cannabis use to be significantly associated with self-reported STIs (aOR, 1.34; 95\% CI, 1.12-1.6). There was a significant association between current drug use and STIs among male (aOR, 3.04; 95\% CI, 2.27-4.06) and female participants (aOR, 1.87; 95\% CI, 1.52-2.30). Having multiple sexual partners, a history of sexual assault, being homosexual, Black, and $>21$ years old were also found to have a significant association with self-reported STIs ( $P$-value $<0.001)$.

Conclusion: In this study, significant associations were found between cannabis and other drug use and STIs among post-secondary students in Canada. The results of this study can help inform institutions of higher learning and public health professionals in the design, implementation, and evaluation of substance use and STI policies and effective school-based health programming. Keywords: substance use, alcohol use, cannabis use, drug use, sexually transmitted infections, post-secondary students

\section{Introduction}

Substance use and sexually transmitted infections (STIs) contribute to the global burden of disease and are responsible for large expenditures and significant strain on health care systems. ${ }^{1,2}$ Substance use poses a significant threat to physical and mental health ${ }^{3}$ and is reported to affect nearly 250 million people annually. ${ }^{4}$ STIs are the most prevalent communicable diseases worldwide, ${ }^{5}$ infecting more than 360 million people annually. ${ }^{6}$ Young adults (aged 20-24 years) including post-secondary students are more likely to engage in risky behaviors such as substance use and unsafe sexual practices, which can lead to an increased risk of STIs. ${ }^{7-9}$ 
STI rates are steadily increasing in Canada. ${ }^{10}$ Specifically, it was reported that between 1998 and 2015, there was a considerable rise in the annual cases of chlamydia and gonorrhea, among all ages and genders. ${ }^{10}$ These findings are particularly troubling because they mainly impact young adult, post-secondary students. According to the Canadian STI surveillance report (2013-2014), the highest rates of chlamydia and gonorrhea were seen among young adults aged 20-24 years. ${ }^{11}$ Chlamydia cases were nearly four times higher among young adults $(1,627.6 / 100,000$ population) compared with adults aged $25-59$ years $\left(431.4 / 100,000\right.$ population). ${ }^{11}$ Likewise, the gonorrhea rates were nearly three times higher among young adults (180.41/100,000 population) compared with adults $(78.8 / 100,000$ population $) .{ }^{11}$

Several risk factors contribute to making young adult, post-secondary students more susceptible to STIs when compared with adults. These include inadequate knowledge, ${ }^{12}$ increased independence, ${ }^{13}$ perceived invulnerability, ${ }^{12}$ inconsistent or inappropriate condom use, ${ }^{14,15}$ access and use of social media to arrange for casual and multiple sexual partners, ${ }^{16-18}$ and sexual encounters under the influence of substance use. ${ }^{8}$ Substance use, in particular, plays a critical role by increasing risky sexual behaviors due to it causing disinhibition and impaired decision-making. ${ }^{14}$

Substance use is a major public health concern and predominately affects young adults including post-secondary students in Canada. ${ }^{19,20}$ The most commonly used substances include alcohol, cannabis, and other drugs (hallucinogens, ecstasy, and cocaine). ${ }^{21}$ The highest percentage of drinking in the last year was among young adults aged 18-24 years $(83 \%) .{ }^{19}$ Similarly, cannabis use in the last year was highest among young adults (25.5\%), who reported rates that were more than two and a half times higher compared with adults $\geq 25$ years old $(10 \% ; 2015) .{ }^{22}$ Likewise, the prevalence of illicit drug use (including cannabis) in the last year for young adults $(27 \%)$ was more than three times higher compared with adults $(8 \% ; 2013) .{ }^{20}$

Young adult, post-secondary students are at an increased risk, and thus, a target population for the prevention and control of STIs. ${ }^{23}$ To reduce the burden of STIs among young adults, it is essential to identify and quantify the relevant risk factors and implement effective intervention strategies. Substance use is an important risk factor for contracting STIs among young adults due to its high prevalence and capacity to link distal contextual factors (ie, emotional and mental health issues) and proximal risky sexual behaviors (ie, unprotected sex). Previous research into substance use and STIs among young adults found positive associations, however, the majority of studies focused on high-risk groups (ie, street youth, minority groups, and problematic drug users). ${ }^{24-28}$ Moreover, there is scarcity of studies in this area in Canada. Therefore, the purpose of this study was to examine the prevalence of substance use preferences (alcohol, cannabis, and other drugs) and its association with STIs among Canadian post-secondary students.

\section{Materials and methods National College Health Assessment II, Spring 2016}

The present study analyzed secondary data from the National College Health Assessment II, Spring 2016 survey, conducted by the American College Health Association (ACHA). It is a national, comprehensive, cross-sectional survey, which collected data using self-administered questionnaires from 41 Canadian post-secondary institutions. The overall response rate was $19.2 \%$. The questionnaire consisted of eight domains: 1) health, health education, and safety; 2) alcohol, tobacco, and drugs; 3) sexual behavior and contraception; 4) weight, nutrition, and exercise; 5) mental health; 6) physical health; 7) impediments to academic performance; and 8) demographic characteristics. The present study specifically focused on the following categories: alcohol, tobacco, and drugs; sexual behavior; physical health; and demographic characteristics. Details about the survey's design and methodology are published elsewhere. ${ }^{29}$

\section{Participants}

In total, there were 43,780 participants from 41 post-secondary institutions in Canada. However, only 31,642 participants were eligible for inclusion in our study. Inclusion criteria were specified as follow: $\geq 18$ years old, students attending Canadian post-secondary institutions, and self-reported sexual activity within the last 12 months.

\section{Measures}

\section{Outcome variable}

The survey asked participants whether they were diagnosed or treated within the last 12 months by a professional for one of the following seven STIs: chlamydia, gonorrhea, HIV, genital herpes, genital warts, hepatitis $\mathrm{B} / \mathrm{C}$, or pelvis inflammatory disease. The response to the questions was dichotomous (yes or no). In our study, these variables were combined to create one variable (being diagnosed or treated with at least one STI in the last 12 months).

\section{Exposure variables}

Our study included preferences for three exposures of interest: 1) alcohol, 2) cannabis, and 3) other drug use. 
Each exposure was further categorized as follows: never (never used), ever (used, but not in the last 30 days), and current users (used, in the last 30 days).

\section{Other covariates}

The present study included sociodemographic and behavioral factors previously recognized in the literature as potential confounders ${ }^{28,30-32}$ associated with our exposures and outcomes of interest. These included the following: age (18-19, 20-21, 22-23, and $\geq 24$ years); biological sex (male or female); ethnicity (White, Black, Hispanic, Aboriginal, Asian/Pacific Islander, Biracial/Multiracial); sexual orientation (heterosexual, homosexual, bisexual, and others); sexual assault in the last 12 months (yes or no); multiple sexual partners (two or more) in the last 12 months (yes or no); and tobacco use in the last 30 days (never, ever, and current users).

\section{Data analysis and model building}

Initially, frequency distributions of self-reported STIs in the last 12 months, substance use preference (alcohol, cannabis, and other drugs), and other covariates were tabulated. A sequence of univariate logistic regression analyses was conducted to measure crude associations between each independent variable and self-reported STIs $(P$-value $<0.25)$. Multicollinearity among independent variables was checked using the variance inflation factor $(\mathrm{VIF}<2.5) .{ }^{33}$ A multivariate logistic regression was used to assess adjusted associations between substance use preferences (alcohol, cannabis, and other drugs) and STIs, while accounting for other covariates.

The variables with $P$-value $>0.05$ were tested for their confounding effect on the associations between substance use preferences (alcohol, cannabis, and other drugs) and STIs before exclusion. If the magnitude of change of the regression coefficients was $\geq 10 \%$ before and after adjusting, the variable was considered a confounder and kept in the model. Two-way interactions between exposures of interest and appropriate independent variables were analyzed and reported ( $P$-value $\leq 0.05$ ). Model fit was assessed using Hosmer-Lemeshow goodness-of-fit statistics ${ }^{34}$ and the model's predicted probability was tested using ROC curve. ${ }^{35}$ Data analysis was conducted using Statistical Analysis System version 9.4.

\section{Results}

\section{Descriptive analysis}

Sexually transmitted infections

There were 31,642 sexually active participants of whom $3.96 \%$ self-reported that they had been diagnosed or treated
Table I Prevalence of self-reported STIs among sexually active Canadian post-secondary students, Spring 2016

\begin{tabular}{|l|l|l|l|}
\hline STI & $\mathbf{N}$ & $\%$ & \% of STI \\
\hline Chlamydia & 623 & 1.98 & 50.04 \\
\hline Genital warts & 336 & 1.07 & 27.01 \\
\hline Genital herpes & 270 & 0.86 & 21.81 \\
\hline Gonorrhea & 136 & 0.43 & 10.92 \\
\hline HBV/HCV & 102 & 0.32 & 8.21 \\
\hline PID & 100 & 0.32 & 8.03 \\
\hline HIV & 86 & 0.27 & 6.91 \\
\hline Total $^{a}$ & 1,250 & 3.96 & - \\
\hline
\end{tabular}

Note: ${ }^{a} \mathrm{~A}$ larger sample size and overlap of frequencies were expected as participants might be co-infected with more than one infection.

Abbreviations: HBV, hepatitis B virus; $\mathrm{HCV}$, hepatitis C virus; HIV, human immunodeficiency virus; PID, pelvic inflammatory disease; STIs, sexually transmitted infections.

for at least one STI in the last 12 months. Chlamydia was the most common self-reported STI (1.98\%). Detailed statistics for STI occurrence among respondents can be seen in Table 1.

\section{Substance use}

Table 2 shows the frequencies for substance use preferences (alcohol, cannabis, and other drugs) among participants. Nearly $80 \%$ of the respondents described themselves as current alcohol users, 23\% current cannabis users, and $8 \%$ current other drug users.

\section{Other characteristics of the study population}

The majority of the participants were female (70.74\%), White (74.64\%), heterosexual (79.9\%), and $\geq 24$ years old (32.18\%). Of the participants, $20.04 \%$ reported tobacco use in the last 30 days, $14.63 \%$ sexual assault in the last 12 months, and $31.30 \%$ multiple sexual partners in the last 12 months. Detailed statistics are presented in Table 3.

Table 2 Prevalence of substance use among sexually active Canadian post-secondary students, Spring 2016

\begin{tabular}{|l|l|l|l|}
\hline \multirow{2}{*}{ Substance use } & \multicolumn{3}{|l|}{ Categories } \\
\cline { 2 - 4 } & $\begin{array}{l}\text { Never used } \\
\text { N (\%) }\end{array}$ & $\begin{array}{l}\text { Ever used } \\
\text { N (\%) }\end{array}$ & $\begin{array}{l}\text { Current used } \\
\text { N (\%) }\end{array}$ \\
\hline Alcohol use & $2,334(7.42)$ & $4,110(13.06)$ & 25,03 I (79.53) \\
\hline Cannabis use & $14,968(47.62)$ & $9,240(29.39)$ & $7,226(22.99)$ \\
\hline Other drug use $^{\mathrm{a}}$ & $24,100(76.34)$ & $4,947(15.67)$ & 2,521 (7.99) \\
\hline
\end{tabular}

Notes: ase of at least one of the following: cocaine (crack, rock, freebase); methamphetamine (crystal meth, ice, crank); other amphetamines (diet pills, bennies); sedatives (downers, ludes); hallucinogens (LSD, PCP); anabolic steroids (testosterone); opiates (heroin, smack); inhalants (flue, solvents, gas); MDMA (ecstasy); other club drugs (GHB, ketamine, rohypnol); or other illegal drugs.

Abbreviations: GHB, gamma-hydroxybutyrate; LSD, D-lysergic acid diethylamide; MDMA, 3,4-methylenedioxy-methamphetamine; PCP, phencyclidine. 
Table 3 Demographic characteristics of sexually active Canadian post-secondary students, Spring 2016

\begin{tabular}{|c|c|c|}
\hline Variables & Categories & $\mathbf{N}(\%)$ \\
\hline \multirow[t]{3}{*}{ Tobacco use } & Never used & I7, II $5(54.31)$ \\
\hline & Ever used & $8,081(25.65)$ \\
\hline & Current used & $6,315(20.04)$ \\
\hline \multirow{2}{*}{$\begin{array}{l}\text { History of sexual assault in } \\
\text { the last } 12 \text { months }\end{array}$} & No & $26,994(85.37)$ \\
\hline & Yes & $4,626(14.63)$ \\
\hline \multirow{2}{*}{$\begin{array}{l}\text { Multiple sexual partners in } \\
\text { the last } 12 \text { months }\end{array}$} & No & $21,578(68.70)$ \\
\hline & Yes & 9,829 (3I.30) \\
\hline \multirow[t]{2}{*}{ Biological sex } & Female & $22,306(70.74)$ \\
\hline & Male & $9,227(29.26)$ \\
\hline \multirow[t]{4}{*}{ Sexual orientation } & Heterosexual & $25,183(79.90)$ \\
\hline & Homosexual & $849(2.69)$ \\
\hline & Bisexual & $2,081(6.60)$ \\
\hline & Others $^{\mathrm{a}}$ & $3,407(10.81)$ \\
\hline \multirow[t]{4}{*}{ Age (years) } & $18-19$ & $6,446(20.47)$ \\
\hline & $20-21$ & $8,972(28.49)$ \\
\hline & $22-23$ & $5,941(18.86)$ \\
\hline & $\geq 24$ & $10,134(32.18)$ \\
\hline \multirow[t]{7}{*}{ Ethnicity } & White & $23,458(74.64)$ \\
\hline & Black & $823(2.62)$ \\
\hline & Aboriginal & $\mathrm{I}, 463(4.65)$ \\
\hline & Hispanic & $722(2.30)$ \\
\hline & Asian & $3,014(9.59)$ \\
\hline & Biracial & $\mathrm{I}, 094(3.48)$ \\
\hline & Other & 855 (2.72) \\
\hline
\end{tabular}

Note: ${ }^{a}$ Asexual, pansexual, queer, questioning, same gender loving another or others.

\section{Univariate analysis}

Univariate analysis was used to measure the crude associations of each independent variable with self-reported STIs. The strongest association was found between having multiple sexual partners and self-reported STIs (OR, 3.57; 95\% CI, 3.17-4). Detailed information regarding crude ORs and their respective 95\% confidence intervals are described in Table 4.

\section{Multivariate analysis}

Association between alcohol use and self-reported STIs

No significant association was found when comparing current or ever users vs never users of alcohol in terms of self-reported STIs (Table 4).

\section{Association between cannabis use} and self-reported STIs

No significant association was found when comparing ever vs never users of cannabis with respect to self-reported STIs.
However, the comparison between current vs never users was significant (aOR, 1.34; 95\% CI, 1.12-1.60; Table 4).

\section{Association between other drug use and self-reported STls}

The two-way interaction between biological sex and other drug use was significant. Therefore, adjusted ORs for the association between other drug use and self-reported STIs were analyzed for male and female participants. For male students, a significant association was found only when comparing current vs never users (aOR, 3.04; 95\% CI, 2.27-4.06). For female students, significant associations were detected for both ever vs never users (aOR, 1.64; 95\% CI, 1.37-1.96) and current vs never users (aOR, 1.87; 95\% CI, 1.52-2.30; Table 4).

\section{Associations between other covariates and self-reported STIs}

Participants who had multiple sexual partners in the last 12 months were nearly three times more likely to be diagnosed or treated for an STI compared with participants who did not (aOR, 2.95; 95\% CI, 2.59-3.37). Participants who experienced sexual assault in the last 12 months were 57\% more likely to report an STI compared with participants who did not (aOR, 1.57; 95\% CI, 1.36-1.81). Homosexuals were two times more likely to be diagnosed or treated for an STI compared with heterosexuals (aOR, 2.04; 95\% CI, 1.55-2.67), whereas other sexual orientations did not show significant difference from heterosexuals. STI risk was higher in Black compared with White students (aOR, 1.59; 95\% CI, 1.15-2.20); however, no significant association was found for other ethnicities. The respondents who were 20-21 years old (aOR, 1.68; 95\% CI, 1.39-2.03), 22-23 years old (aOR, 1.93 ; 95\% CI, 1.57-2.36), and $\geq 24$ years (aOR, 2.36; 95\% CI, 1.95-2.85) were significantly more likely to self-report an STI compared with respondents who were 18-19 years old (Table 4).

\section{Discussion}

Our study found that $93 \%$ of the sexually active, postsecondary students were lifetime alcohol users (current and ever users). This rate is close to the national average, which estimates that $91 \%$ of Canadians aged $\geq 15$ years have used alcohol in their lifetime. ${ }^{36}$

However, the association between alcohol use and STIs was not significant in our study after adjusting for covariates. It is possible that recently launched health promotion initiatives and national guidelines related to alcohol use and 
Table 4 Crude and adjusted associations of substance use and other covariates with self-reported STIs among sexually active Canadian post-secondary students

\begin{tabular}{|c|c|c|c|c|c|}
\hline Variables & Categories & $\begin{array}{l}\text { Crude OR } \\
(95 \% \mathrm{Cl})\end{array}$ & $\begin{array}{l}P \text {-value } \\
(\alpha=0.25)\end{array}$ & $\begin{array}{l}\text { Adjusted OR } \\
(95 \% \mathrm{Cl})\end{array}$ & $\begin{array}{l}P \text {-value } \\
(\alpha=0.05)\end{array}$ \\
\hline \multirow[t]{3}{*}{ Alcohol use } & Never used & 1 & \multirow[t]{3}{*}{$<0.000 \mathrm{I}$} & 1 & \multirow[t]{3}{*}{$>0.05$} \\
\hline & Ever used & $0.92(0.67-1.25)$ & & $0.69(0.50-0.96)$ & \\
\hline & Current used & $1.53(1.19-1.96)$ & & $0.8 \mathrm{I}(0.6 \mathrm{I}-\mathrm{I} .07)$ & \\
\hline \multirow[t]{3}{*}{ Cannabis use } & Never used & I & \multirow[t]{3}{*}{$<0.0001$} & 1 & \multirow[t]{3}{*}{$<0.01$} \\
\hline & Ever used & $1.67(1.44-1.92)$ & & $1.14(0.96-1.35)$ & \\
\hline & Current used & $2.67(2.32-3.06)$ & & $1.34(1.12-1.6)$ & \\
\hline \multirow[t]{3}{*}{ Other drug use $\mathrm{e}^{\mathrm{a}}$} & Never used & 1 & \multirow[t]{3}{*}{$<0.0001$} & \multirow[t]{3}{*}{-} & \multirow[t]{3}{*}{-} \\
\hline & Ever used & $2.17(1.89-2.5)$ & & & \\
\hline & Current used & $3.87(3.33-4.5)$ & & & \\
\hline \multicolumn{2}{|l|}{ Other drug use by biological sex } & - & - & - & \multirow[t]{7}{*}{$<0.001$} \\
\hline \multirow[t]{3}{*}{ Other drug use ${ }^{a}$ (male) } & Never used & \multirow[t]{3}{*}{-} & \multirow[t]{3}{*}{-} & & \\
\hline & Ever used & & & $1.12(0.81-1.54)$ & \\
\hline & Current used & & & $3.04(2.27-4.06)$ & \\
\hline \multirow[t]{3}{*}{ Other drug use ${ }^{\mathrm{a}}$ (female) } & Never used & \multirow[t]{3}{*}{-} & \multirow[t]{3}{*}{-} & 1 & \\
\hline & Ever used & & & $1.64(1.37-1.96)$ & \\
\hline & Current used & & & $1.87(1.52-2.30)$ & \\
\hline \multirow[t]{3}{*}{ Tobacco use } & Never used & 1 & \multirow[t]{3}{*}{$<0.0001$} & 1 & \multirow[t]{3}{*}{$>0.05$} \\
\hline & Ever used & $1.47(1.28-1.69)$ & & $1.02(0.87-1.20)$ & \\
\hline & Current used & $2.25(1.97-2.57)$ & & $1.13(0.96-1.33)$ & \\
\hline \multirow{2}{*}{$\begin{array}{l}\text { Multiple sexual partners in the } \\
\text { last } 12 \text { months }\end{array}$} & No & 1 & \multirow[t]{2}{*}{$<0.0001$} & 1 & \multirow[t]{2}{*}{$<0.0001$} \\
\hline & Yes & $3.57(3.17-4.00)$ & & $2.95(2.59-3.37)$ & \\
\hline \multirow{2}{*}{$\begin{array}{l}\text { History of sexual assault in the } \\
\text { last } 12 \text { months }\end{array}$} & No & 1 & \multirow[t]{2}{*}{$<0.0001$} & 1 & $<0.0001$ \\
\hline & Yes & $2.46(2.17-2.79)$ & & $1.57(1.36-1.8 \mathrm{I})$ & \\
\hline Age (years) & $18-19$ & 1 & $<0.0001$ & 1 & $<0.0001$ \\
\hline & $20-21$ & $1.54(1.28-1.85)$ & & $1.68(1.39-2.03)$ & \\
\hline & $22-23$ & $1.67(1.38-2.03)$ & & $1.93(1.57-2.36)$ & \\
\hline & $\geq 24$ & $1.67(1.40-2.00)$ & & $2.36(1.95-2.85)$ & \\
\hline Biological sex & Male & 1 & $<0.01$ & 1 & - \\
\hline & Female & $1.19(1.05-1.36)$ & & - & \\
\hline Sexual orientation & Heterosexual & 1 & $<0.0001$ & 1 & $<0.0001$ \\
\hline & Homosexual & $2.51(1.95-3.23)$ & & $2.04(1.55-2.67)$ & \\
\hline & Bisexual & $1.57(1.28-1.92)$ & & $1.04(0.85-1.29)$ & \\
\hline & Other ${ }^{b}$ & $1.35(1.14-1.61)$ & & $1.10(0.92-1.32)$ & \\
\hline Ethnicity & White & 1 & $<0.0001$ & 1 & $<0.05$ \\
\hline & Black & $1.51(1.12-2.04)$ & & $1.59(1.15-2.20)$ & \\
\hline & Hispanic & $1.14(0.95-1.58)$ & & $1.34(0.94-1.91)$ & \\
\hline & Aboriginal & $1.37(1.08-1.74)$ & & $1.24(0.96-1.59)$ & \\
\hline & $\begin{array}{l}\text { Asian/Pacific } \\
\text { Islander }\end{array}$ & $0.69(0.55-0.87)$ & & $0.88(0.69-1.12)$ & \\
\hline & Bi/multiracial & $1.37(1.04-1.80)$ & & $1.17(0.87-1.56)$ & \\
\hline & Other & $1.16(0.83-1.61)$ & & I.09 (0.77-I.55) & \\
\hline
\end{tabular}

Notes: Alcohol use and tobacco use were confounders for the cannabis use and other drug use. ase of at least one of the following: cocaine (crack, rock, freebase); methamphetamine (crystal meth, ice, crank); other amphetamines (diet pills, bennies); sedatives (downers, ludes); hallucinogens (LSD, PCP); anabolic steroids (testosterone); opiates (heroin, smack); inhalants (flue, solvents, gas); MDMA (ecstasy); other club drugs (GHB, ketamine, rohypnol); or other illegal drugs. 'Asexual, pansexual, queer, questioning, same gender loving another or others.

Abbreviations: GHB, gamma-hydroxybutyrate; LSD, D-lysergic acid diethylamide; MDMA, 3,4-methylenedioxy-methamphetamine; PCP, phencyclidine; STIs, sexually transmitted infections. 
its associated risk to STIs have helped increase awareness and improve knowledge among post-secondary students in Canada. ${ }^{37-40}$ Other studies contradict our finding and provide evidence that show alcohol use to be associated with STIs. ${ }^{24-28}$ However, these studies used different target populations including street youth, ${ }^{24}$ youth living with HIV, ${ }^{25}$ African American youth, ${ }^{26,27}$ and Aboriginal youth. ${ }^{28}$ The differences in the demographics of these study populations suggest that post-secondary students are a distinct group and the findings from other vulnerable populations of similar age may not be generalizable to them.

According to our findings, the prevalence of lifetime cannabis use (53\%) was higher among sexually active post-secondary students compared with the national statistics (44.5\%). ${ }^{41} \mathrm{As}$ Canada plans to legalize the recreational cannabis in $2018,{ }^{42}$ higher rates of cannabis use may be anticipated due to easier access, higher social acceptance, lower prices, and decreased perceived harm. ${ }^{43-45}$ Therefore, it is important to continue to research the health consequences of cannabis use and raise awareness, among post-secondary students. In our study, current cannabis users were $32 \%$ more likely to self-report STIs in the last 12 months compared with never users. Our findings are consistent with those reported in previous studies. ${ }^{25-28}$ There are different possible explanations for our results. One hypothesis suggests that cannabis acts as a potential immunosuppressant, reducing proinflammatory immune markers responsible for fighting infectious agents, making users more susceptible to STIs. ${ }^{46,47}$ Secondly, it is postulated that cannabis use leads to increased risky sexual behaviors (ie, unprotected sex) due to disinhibition and impaired decision-making, which may result in increased risk to contract STIs. ${ }^{26,48}$

Among our study population, $8 \%$ reported currently using other drugs. Our analysis found that male (three times) and female (two times) current other drug users were significantly more likely to self-report STIs in the last 12 months compared with never users. According to the literature, when males use illicit drugs, they tend to use them with greater frequency, magnitude, and are more likely to engage in simultaneous poly-drug use compared with females ${ }^{49,50}$ Our results suggest that 1 in 12 post-secondary students engage in current other drug use regardless of their knowledge and setting. These students are a vulnerable group and prime candidates to benefit from school-based health interventions that address other drug use and STIs.

Additionally, our study revealed a number of interesting findings. The prevalence of self-reported chlamydia $(1,980 / 100,000)$ and gonorrhea $(430 / 100,000)$ infections among sexually active Canadian post-secondary students were significantly higher than those reported among the general population (668/100,000 and $87 / 100,000$, respectively). ${ }^{11}$ Among post-secondary students, having multiple sexual partners had the strongest association with STIs. This result may be attributed to the influence of peers, absence of parental supervision, a growing hook-up culture, and mental stressors. ${ }^{51,52}$ When examining sexual orientation, homosexuals were more likely to report STIs, which is consistent with the findings reported in the literature. ${ }^{12}$ These findings reflect an opportunity to design and implement specifically tailored health promotion activities and safe sex practices that address the unique needs of post-secondary students in Canada.

\section{Strengths and limitations}

The strengths of our study include: 1) a population of interest that is vulnerable and to date not well characterized in Canada; 2) a large, national sample size representing 41 post-secondary institutions across Canada; 3) the diverse background of its participants (ie, inclusion of both sexes, different sexual orientations, and different ethnic groups); 4) the use of a survey instrument that is robust, valid, and reliable; and 5) the inclusion of different substance use variables (alcohol, cannabis, and other drugs) in the multivariate logistic regression analysis, which ensured pure estimates (odds ratios). There were also several limitations to this study: 1) it used a cross-sectional design and thus, reported on associations but cannot infer causation; 2) it relied on self-reported responses on substance use and STIs, which may underestimate the extent of the problem due to stigmatization, social desirability, and recall bias; 3) it was unable to analyze the magnitude of substance use and the event-specific sequence (ie, if substance use immediately preceded contracting an STI or not); and 4) it had a rather low participation rate $(19.2 \%)$.

\section{Implications for future research}

Future research among post-secondary students in Canada is warranted to examine the following: 1) the association between substance use and STIs by using specific measures (ie, magnitude, severity, and event-specific sequence of substance use and clinically diagnosed STIs); 2) the long-term impact of cannabis use on health-related outcomes including STIs; 3 ) the association between specific illicit drug use and STIs; and 4) the relationship between socioeconomic and environmental factors on substance use and STI occurrence.

\section{Conclusion}

In this study, a significant association was found between cannabis and other drug use and STIs among post-secondary students in Canada. The results of this study can help inform 
institutions of higher learning and public health professionals in the design, implementation, and evaluation of substance use and STI policies and effective school-based health programming. Future initiatives need to emphasize both collaboration and integration of substance use and STI services to improve the overall health and well-being of post-secondary students.

\section{Ethics statement}

This study is exempt from ethics approval because it relies on the use of ACHA micro-files and secondary analysis of anonymous data (Tri-Council Policy Statement, articles 2.2 and 2.4, respectively). Participation in this survey was voluntary.

\section{Acknowledgments}

We gratefully acknowledge the support of Ms Rita Hanoski, Health Education and Promotion Coordinator and Ms Jocelyn Orb, Manager, Student Health Services, University of Saskatchewan. This research was supported in part by an internal grant from the School of Public Health, University of Saskatchewan. The opinions, findings, and conclusions presented/ reported in this article are those of the authors, and are in no way meant to represent the corporate opinions, views, or policies of the ACHA. ACHA does neither warrant nor assume any liability or responsibility for the accuracy, completeness, or usefulness of any information presented in this article.

\section{Author contributions}

All authors contributed to data analysis, drafting and revising the article, gave final approval of the version to be published, and agree to be accountable for all aspects of the work.

\section{Disclosure}

The authors report no conflicts of interest in this work.

\section{References}

1. World Health Organization [webpage on the Internet]. Report on Global Sexually Transmitted Infection Surveillance 2015. Geneva: World Health Organization; 2016. Available from: http://www.who.int/reproductivehealth/ publications/rtis/stis-surveillance-2015/en/. Accessed July 28, 2018.

2. World Health Organization (WHO) [webpage on the Internet]. The Global Burden. Geneva: World Health Organization; 2010. Available from: http://www.who.int/substance_abuse/facts/global_burden/en/. Accessed July 28, 2018.

3. Degenhardt L, Whiteford HA, Ferrari AJ, et al. Global burden of disease attributable to illicit drug use and dependence: findings from the Global Burden of Disease Study 2010. Lancet. 2013;382(9904): $1564-1574$.

4. World Health Organization [webpage on the Internet]. Management of Substance Abuse. Geneva: World Health Organization; 2018. Available from: http://www.who.int/substance_abuse/en/. Accessed July 28, 2018.

5. Taylor MM, Korenromp E, Wi T. Pathways and progress to enhanced global sexually transmitted infection surveillance. PLoS Med. 2017; 14(6):e1002328.
6. Smith J [webpage on the Internet]. STD Statistics Worldwide INFOGRAPHIC. Infographics Archive; 2012. Available from: https:// www.infographicsarchive.com/health-beauty-safety/std-statisticsworldwide/. Accessed June 23, 2018.

7. Centers for Disease Control and Prevention [webpage on the Internet] 2016 Sexually Transmitted Diseases Surveillance. Atlanta, GA: Centers for Disease Control and Prevention; 2017. Available from: https://www. cdc.gov/std/stats16/adolescents.htm. Accessed July 28, 2018.

8. Goldstein AL, Barnett NP, Pedlow CT, Murphy JG. Drinking in conjunction with sexual experiences among at-risk college student drinkers. J Stud Alcohol Drugs. 2007;68(5):697-705.

9. Cooper ML. Alcohol use and risky sexual behavior among college students and youth: evaluating the evidence. J Stud Alcohol Suppl. 2002; (14):101-117.

10. Racco M [webpage on the Internet]. Why STI Rates Are Steadily Going Up in Canada. Global News; 2017. Available from: https://globalnews. ca/news/3797824/why-sti-infection-rates-are-steadily-going-up-incanada/. Accessed July 28, 2018.

11. Public Health Agency of Canada (PHAC) [webpage on the Internet]. Report on Sexually Transmitted Infections in Canada: 2013-2014. Government of Canada; 2017. Available from: https://www.canada. $\mathrm{ca} /$ en/public-health/services/publications/diseases-conditions/reportsexually-transmitted-infections-canada-2013-14.html. Accessed June 24, 2018.

12. Boyce W, Doherty M, Fortin C, MacKinnon D. Canadian Youth, Sexual Health and HIVIAIDS Study: Factors Influencing Knowledge, Attitudes and Behaviours. Toronto: Council of Ministers of Education, Canada; 2003:150. Available from: https://www.cmec.ca/Publications/Lists/ Publications/Attachments/180/CYSHHAS_2002_EN.pdf. Accessed June 24, 2018.

13. Oswalt SB. Beyond risk: examining college students' sexual decision making. Am J Sex Educ. 2010;5(3):217-239.

14. Public Health Agency of Canada (PHAC) [webpage on the Internet]. Canadian guidelines on sexually transmitted infections - section 2: primary care and sexually transmitted infections. Public Health Agency of Canada; 2018. Available from: https://www.canada.ca/en/public-health/services/ infectious-diseases/sexual-health-sexually-transmitted-infections/ canadian-guidelines/sexually-transmitted-infections/canadian-guidelinessexually-transmitted-infections-17.html. Accessed June 23, 2018.

15. Genuis SJ, Steiner MJ, Cates W. Are condoms the answer to rising rates of non-HIV sexually transmitted infection? No. BMJ. 2008;336(7637): 184-185.

16. Veinot TC, Campbell TR, Kruger D, Grodzinski A, Franzen S. Drama and danger: the opportunities and challenges of promoting youth sexual health through online social networks. AMIA Annu Symp Proc. 2011;2011: 1436-1455.

17. McFarlane M, Bull SS, Rietmeijer CA. Young adults on the Internet: risk behaviors for sexually transmitted diseases and $\mathrm{HIV}(1)$. $J$ Adolesc Health. 2002;31(1):11-16.

18. Frank S. Hyper-texting and hyper-networking examining why too much texting and social networking is associated with teen risk behavior. 2013 Nov 05. Presented at: 141st APHA Annual Meeting and Exposition; November 2-6, 2013; Boston, MA.

19. Canadian Centre on Substance Use and Addiction. Alcohol - Canadian Drug Summary; 2017. Available from: http://www.ccdus.ca/ Resource\%20Library/CCSA-Canadian-Drug-Summary-Alcohol2017-en.pdf. Accessed June 23, 2018.

20. Government of Canada [webpage on the Internet]. Canadian Tobacco Alcohol and Drugs (CTADS): 2013 Summary; 2013. Available from: https://www.canada.ca/en/health-canada/services/canadian-tobaccoalcohol-drugs-survey/2013-summary.html. Accessed June 23, 2018.

21. Canadian Centre on Substance Abuse and Addiction (CCSA). Trends in Drug Use among Youth; 2013. Available from: http://www.ccsa.ca/ Resource\%20Library/CCSA-Trends-in-Drug-Use-Youth-2012-en.pdf. Accessed July 27, 2018.

22. CCSA. Cannabis (Canadian Drug Summary). Available from: http:// www.ccsa.ca/Resource\%20Library/CCSA-Canadian-Drug-SummaryCannabis-2018-en.pdf. Accessed June 23, 2018. 
23. World Health Organization [webpage on the Internet]. Global Health Sector Strategy on Sexually Transmitted Infections 2016-2021. Geneva: World Health Organization; 2016. Available from: http:/apps.who.int/ iris/bitstream/10665/246296/1/WHO-RHR-16.09-eng.pdf. Accessed June 23, 2018.

24. Public Health Agency of Canada (PHAC) [webpage on the Internet]. Street Youth in Canada; 2006. Available from: https://www.canada.ca/ en/public-health/services/infectious-diseases/sexual-health-sexuallytransmitted-infections/youth-canada.html. Accessed July 28, 2018.

25. Gamarel KE, Nichols S, Kahler CW, et al; Adolescent Medicine Trials Network for HIV/AIDS Intervention. A cross-sectional study examining associations between substance use frequency, problematic use and STIs among youth living with HIV. Sex Transm Infect. 2018; 94(4):304-308.

26. Keen L 2nd, Blanden G, Rehmani N. Lifetime marijuana use and sexually transmitted infection history in a sample of Black college students. Addict Behav. 2016;60:203-208.

27. Khan MR, Berger AT, Wells BE, Cleland CM. Longitudinal associations between adolescent alcohol use and adulthood sexual risk behavior and sexually transmitted infection in the United States: assessment of differences by race. Am J Public Health. 2012;102(5):867-876.

28. Wand $\mathrm{H}$, Ward J, Bryant J, et al. Individual and population level impacts of illicit drug use, sexual risk behaviours on sexually transmitted infections among young Aboriginal and Torres Strait Islander people: results from the GOANNA survey. BMC Public Health. 2016;16:600.

29. American College Health Association - National College Health Assessment II (ACHA - NCHA II). ACHA-NCHA, Spring 2016 Survey. Available from: https://www.acha.org/NCHA/About_ACHA_NCHA/ Survey/NCHA/About/Survey.aspx?hkey=7e9f6752-2b47-4671-8ce7ba7a529c9934. Accessed July 21, 2018.

30. Falasinnu T, Gilbert M, Hottes TS, Gustafson P, Ogilvie G, Shoveller J. Predictors identifying those at increased risk for STDs: a theory-guided review of empirical literature and clinical guidelines. Int J STD AIDS. 2015;26(12):839-851.

31. Wynne A, Currie CL. Social exclusion as an underlying determinant of sexually transmitted infections among Canadian aboriginals. Pimatisiwin: J Aborig Indigenous Community Health. 2011;9(1):113-127.

32. Allen UD, MacDonald NE, Canadian Paediatric Society, Infectious Diseases and Immunization Committee. Sexually transmitted infections in adolescents: maximizing opportunities for optimal care. Paediatr Child Health. 2014;19(8):429-433.

33. Midi H, Sarkar SK, Rana S. Collinearity diagnostics of binary logistic regression model. J Interdiscip Math. 2010;13(3):253-267.

34. Hosmer D, Lemeshow S, Sturdivant R. Applied Logistic Regression. 3rd ed. Hoboken, NJ: Wiley; 2013.

35. Tape $\mathrm{T}$ [webpage on the Internet]. The Area Under a ROC Curve. Available from: http://gim.unmc.edu/dxtests/roc3.htm. Accessed July 28, 2018.

36. Li S [webpage on the Internet]. Alcohol consumption in Canada. RPubs; 2017. Available from: https://rpubs.com/susan_li/alcohol-consumptioncanada. Accessed June 23, 2018.

37. Ontario Agency for Health Protection and Promotion (Public Health Ontario). Effectiveness of Approaches to Communicate Alcohol-Related Health Messaging: Review and Implications for Ontario's Public Health Practitioners, 2014 Revision. Toronto, ON: Queen's Printer for Ontario; 2015.

Patient Preference and Adherence

\section{Publish your work in this journal}

Patient Preference and Adherence is an international, peer-reviewed, open access journal that focuses on the growing importance of patient preference and adherence throughout the therapeutic continuum. Patient satisfaction, acceptability, quality of life, compliance, persistence and their role in developing new therapeutic modalities and compounds to optimize
38. CCSA [webpage on the Internet]. Drinking Guidelines in Canada. Available from: http://www.ccsa.ca/Eng/topics/alcohol/drinkingguidelines/Pages/default.aspx. Accessed June 29, 2018.

39. Nova Scotia, Canada. A Summary of Best Practices: Reducing Alcohol Harms among University Students; 2012. Available from: https:// novascotia.ca/dhw/addictions/documents/Reducing-alcohol-harmsamong-university-students.pdf. Accessed July 28, 2018.

40. British Columbia, Canada. Alcohol on Campus: Programs and Policies Review and Recommendations. BC, Canada: Centre for Addictions Research of BC; 2008. Available from: https://www.uvic.ca/research/ centres/cisur/assets/docs/report-alcohol-on-campus.pdf. Accessed July 28, 2018.

41. Statista. Lifetime Illegal Drug Use Canada 201. Available from: https:// www.statista.com/statistics/812280/lifetime-illegal-drug-use-canada/. Accessed June 25, 2018.

42. University of Saskatchewan [webpage on the Internet]. Legalizing Cannabis in Canada: Regulate, Educate, Mitigate and Innovate. Graduate School of Public Policy. Available from: https://www. schoolofpublicpolicy.sk.ca/research/publications/policy-brief/ Legalizing-Cannabis-in-Canada.php. Accessed July 29, 2018.

43. Hopfer C. Implications of Marijuana Legalization for Adolescent Substance Use. Available from: https://www.ncbi.nlm.nih.gov/pmc/articles/ PMC4308295/pdf/nihms622137.pdf. Accessed July 28, 2018.

44. Khazan O [webpage on the Internet]. The Surprising Effect of Marijuana Legalization on College Students. The Atlantic. Atlantic Media Company; 2017. Available from: https://www.theatlantic.com/health/ archive/2017/06/marijuana-legalization-college-students/530607/. Accessed July 29, 2018.

45. Hajizadeh M. Legalizing and regulating marijuana in Canada: review of potential economic, social, and health impacts. Int J Health Policy Manag. 2016;5(8):453-456.

46. Suárez-Pinilla P, López-Gil J, Crespo-Facorro B. Immune system: a possible nexus between cannabinoids and psychosis. Brain Behav Immun. 2014;40:269-282.

47. Keen L, Turner AD. Differential effects of self-reported lifetime marijuana use on interleukin-1 alpha and tumor necrosis factor in African American adults. J Behav Med. 2015;38(3):527-534.

48. Ross JM, Duperrouzel J, Vega M, Gonzalez R. The neuropsychology of risky sexual behavior. J Int Neuropsychol Soc. 2016;22(6):586-594.

49. Guimarães RA, de Oliveira Landgraf de Castro V, do Valle Leone de Oliveira SM, et al. Gender differences in patterns of drug use and sexual risky behaviour among crack cocaine users in Central Brazil. BMC Psychiatry. 2017;17(1):412.

50. McCabe SE, Cranford JA, Morales M, Young A. Simultaneous and concurrent polydrug use of alcohol and prescription drugs: prevalence, correlates, and consequences. J Stud Alcohol. 2006;67(4):529-537.

51. Bailey JA, Haggerty KP, White HR, Catalano RF. Associations between changing developmental contexts and risky sexual behavior in the two years following high school. Arch Sex Behav. 2011;40(5):951-960.

52. Garcia JR, Reiber C, Massey SG, Merriwether AM. Sexual hookup culture: a review. Rev Gen Psychol. 2012;16(2):161-176.

\section{Dovepress}

clinical outcomes for existing disease states are major areas of interest for the journal. This journal has been accepted for indexing on PubMed Central. The manuscript management system is completely online and includes a very quick and fair peer-review system, which is all easy to use. Visit http://www. dovepress.com/testimonials.php to read real quotes from published authors. 